\title{
A Single Buyer-Single Supplier Bargaining Problem with Asymmetric Information - Theoretical Approach and Software Implementation
}

\author{
Eric Sucky, Department of Supply Chain Management, Goethe-University, Mertonstr. 17, \\ 60054 Frankfurt, Germany, Phone: 0049 (0)69 798 28201, esucky@wiwi.uni-frankfurt.de
}

\begin{abstract}
This paper is focused on the coordination of order and production policy between buyers and suppliers in supply chains. When a buyer and a supplier of an item work independently, the buyer will place orders based on his economic order quantity (EOQ). However, the buyer's EOQ may not lead to an optimal policy for the supplier. It can be shown that a cooperative batching policy can reduce total cost significantly. Should the buyer have the more powerful position to enforce his EOQ on the supplier, then no incentive exists for him to deviate from his EOQ in order to choose a cooperative batching policy. To provide an incentive to order in quantities suitable to the supplier, the supplier could offer a side payment. One critical assumption made throughout in the literature dealing with incentive schemes to influence buyer's ordering policy is that the supplier has complete information regarding buyer's cost structure. However, this assumption is far from realistic. As a consequence, the buyer has no incentive to report truthfully on his cost structure. Moreover there is an incentive to overstate the total relevant cost in order to obtain as high a side payment as possible. This paper provides a bargaining model with asymmetric information about the buyer's cost structure assuming that the buyer has the bargaining power to enforce his EOQ on the supplier in case of a break-down in negotiations. An algorithm for the determination of an optimal set of contracts which are specifically designed for different cost structures of the buyer, assumed by the supplier, will be presented. This algorithm was implemented in a software application, that supports the supplier in determining the optimal set of contracts.
\end{abstract}

\section{Introduction}

The term supply chain management refers to cooperative management of materials and information flow between supply chain partners, to reach goals that cannot be achieved acting singly. This paper is focused on the supply chain from the perspective of inventory management. In contrast to multiechelon inventory management, that coordinates inventories at multiple locations of one firm, a joint inventory replenishment policy in supply chains involves coordination among multiple firms [15; pp. 794795]. Therefore both in the scientific discussion and in practice the coordination of order policy and production policy between buyers and suppliers is especially interesting [16; pp. 146-147].

When the buyer and supplier inventory problems are treated in isolation, under deterministic conditions, it is well known that the economic order quantity (EOQ) formula or the economic lot size (ELS) formula gives an optimal solution. However, in general, an order policy based on the EOQ solution is unacceptable to the supplier, and likewise, a production and delivery policy based on the ELS solution is unacceptable to the buyer [17; p. 312]. The problem of coordination between the order policy and the production policy of a buyer and a supplier has received considerable attention in recent years. Detailed reviews of integrated buyer-supplier inventory models are given by Goyal/Gupta [10], Joglekar/Thartare [14], Thomas/Griffin [23] and Sharafali/Co [21]. A number of authors, including Goyal [8], Banerjee [2], Goyal [9], Landeros/Lyth [16], Chatterjee/Ravi [5] and Agrawal/Raju [1], suggest under different conditions some joint economic lot size (JELS) models where the objective is to minimize the total relevant costs for both the buyer and the supplier. It is shown that a coordinated or integrated inventory replenishment policy is more desirable than individual optimal policies of the parties involved. Nevertheless, should one of the parties involved have the more powerful position to enforce his EOQ or ELS on the other party, then no incentive exists for these party to choose a cooperative batching policy. Essentially, the more powerful party will be at a disadvantage if the JELS solution is adopted. However, by adopting the JELS solution the more powerful party's loss is more than offset by the gain of the other party [2; p. 309-310]. Thus, to provide an incentive to choose a joint policy the advantaged party can offer a side payment to the disadvantaged party. Therefore the order and delivery quantities and the side payment are determined through a bargaining process between the buyer and the supplier.

The supplier's problem to influence the buyer's order policy by a price discount or side payment scheme is analyzed by previous authors, including Monahan [19], Banerjee [3], Lee/Rosenblatt [18] and Joglekar [13]. However, one critical assumption made throughout in the literature 
dealing with incentive schemes to influence buyer's ordering policy is that the supplier has complete information about the buyer's cost structure [6; p. 1]. However, it is very difficult to estimate buyer's holding and ordering costs unless the buyer is willing to reveal the true values of his own cost parameters [17; p. 313]. Because this assumption is far from realistic, it can be assumed that opportunistic behavior will emerge and be accompanied by incomplete and falsified information. As a consequence, the buyer has no incentive to report truthfully on his cost structure. Instead there is an incentive for him to overstate his total relevant cost in order to obtain as high a side payment as possible. Side payment problems can be considered as two-person-nonzero-sum games in which both players, the buyer and the supplier, try to maximize their individual gains. Corbett/de Groote [6] present a game theoretical analysis with information asymmetry about buyer's holding cost. Nevertheless, the buyer's ordering costs are assumed as common knowledge. In this case, the problem of information asymmetry is eliminated. The buyer's holding cost can be specified as an implicit function of his ordering cost and his EOQ. Thus, if the supplier knows buyer's holding cost and his EOQ, the supplier can also derive buyer's ordering cost.

The research presented in this paper provides a bargaining model with asymmetric information about the buyer's ordering cost and holding cost, assuming that the buyer has the bargaining power to enforce his EOQ on the supplier in case of a break-down in negotiations. If the supplier has incomplete information about the buyer's cost structure, the buyer can have different functions of total relevant cost, assumed by the supplier. In order to set an incentive for report truthfully, the supplier can employ self-selection or screening [12; pp. 561-562]: the supplier determines several contracts which are specifically designed for the different assumed cost structures. The supplier must design incentive-compatible contracts which make it attractive for the buyer to choose the contract which is designed for his specific cost structure. Thus, the supplier has to offer order quantities and side payments which guarantee that the buyer accepts the adequate contract. It will be shown that the supplier can determine an optimal set of contracts for the assumed cost structures. An algorithm for the determination of the optimal set of contracts will be presented. This algorithm was implemented in a software based application, that supports the supplier in determining the optimal set of contracts for different assumed cost structures.

\section{Optimal ordering and production policies}

In this section we will formally introduce the problem of coordinating the order policy and the production policy of a buyer and a supplier. First, the order policy of the buyer, based on his EOQ solution, and the production and delivery policy of the supplier, based on his ELS solution, will be presented. In order to compare a joint economic order and production policy with the individual policies, the individual policies, the JELS solution will be presented. We will show that neither party has an incentive to choose the JELS solution.

\subsection{Individual optimal ordering policy}

The discussion and analysis in this paper is restricted to the case of a single supplier (V) and single buyer (B) of a specific product. The periodical demand for the product is assumed constant and deterministic. Shortages are not permitted at the buyer's end, and the time horizon over which the product is ordered by the buyer and supplied by the supplier is infinite. The lead time for the buyer is zero. In a situation where the buyer operate independently, the total relevant cost per period, $\mathrm{TRC}_{\mathrm{B}}\left(\mathrm{Q}_{\mathrm{B}}\right)$, for any order quantity $\mathrm{Q}_{\mathrm{B}}$ is given by

$\mathrm{TRC}_{\mathrm{B}}\left(\mathrm{Q}_{\mathrm{B}}\right)=\frac{\mathrm{A} \cdot \mathrm{D}}{\mathrm{Q}_{\mathrm{B}}}+\frac{\mathrm{Q}_{\mathrm{B}}}{2} \cdot \mathrm{H}_{\mathrm{B}}$

where

$\mathrm{D}:$ demand per period [unit/period]

A : buyer's ordering cost per order $[\$]$

$\mathrm{Q}_{\mathrm{B}}$ : buyer's order quantity per order [unit]

$\mathrm{H}_{\mathrm{B}}$ : buyer's inventory holding cost [\$/unit and period]

The objective of the buyer is to minimize his total relevant cost per period. It is easy to see that for an optimal ordering policy every order is received precisely when the inventory level drops to zero [4; pp. 145-147]. The EOQ and the minimum total relevant cost per period are given by

$\mathrm{Q}_{\mathrm{B}}^{*}=\sqrt{\frac{2 \cdot \mathrm{A} \cdot \mathrm{D}}{\mathrm{H}_{\mathrm{B}}}}, \operatorname{TRC}_{\mathrm{B}}\left(\mathrm{Q}_{\mathrm{B}}^{*}\right)=\sqrt{2 \cdot \mathrm{A} \cdot \mathrm{D} \cdot \mathrm{H}_{\mathrm{B}}}$.

\subsection{Individual optimal production and delivery policy}

The supplier (V) manufactures the regarded product, at a finite production rate $P$, in batches of $Q_{V}$ and incurs a batch set up cost. It is assumed that $\mathrm{P}>\mathrm{D}$. For solving a production and delivery policy for the supplier it has to be considered whether lot streaming is allowed or not. In case of lot streaming, assuming a uninterrupted production run, shipments can be made from a production batch before the whole batch is finished. However, some suppliers cannot accommodate lot streaming because of regulations, material handling equipment, or production requirements $[22 ; \mathrm{p}$. 657]. Without lot streaming the whole production batch must be finished before any shipments can be made from the batch $[11 ;$ p. 493]. In this paper it is assumed that the supplier follows a lot-for-lot-policy, i. e. after finishing the whole production batch the supplier ships the entire lot to the buyer. There are still costs associated with processing those shipments [16; p. 151]. Thus, the set up costs include fixed delivery costs associated with each shipment, i. e. costs for inspection, packing, handling and shipping the production batch. The objective of the supplier is to find the optimal production and delivery policy minimizing his 
total relevant cost per period that is comprised of set up cost and inventory holding cost. Banerjee [2] shows the average inventory with lot-for-lot production to be:

Average Inventory $=\frac{\mathrm{Q}_{\mathrm{V}}}{2} \cdot \frac{\mathrm{D}}{\mathrm{P}}$.

The total relevant cost per period, $\mathrm{TRC}_{\mathrm{V}}\left(\mathrm{Q}_{\mathrm{V}}\right)$, for any lot size $Q_{V}$ is given by

$\operatorname{TRC}_{\mathrm{V}}\left(\mathrm{Q}_{\mathrm{V}}\right)=\frac{\mathrm{S} \cdot \mathrm{D}}{\mathrm{Q}_{\mathrm{V}}}+\frac{\mathrm{Q}_{\mathrm{V}}}{2} \cdot \frac{\mathrm{D}}{\mathrm{P}} \cdot \mathrm{H}_{\mathrm{V}}$

where

$\mathrm{P}$ : supplier's production rate [unit/period]

$\mathrm{S}$ : supplier's manufacturing set up cost per production run and cost of handling and processing per shipping the whole production lot to B [\$]

$\mathrm{H}_{\mathrm{V}}$ : supplier's inventory holding cost [\$/unit and period] $\mathrm{Q}_{\mathrm{V}}$ : supplier's lot size [unit]

The ELS and the minimum total relevant cost per period are given by

$\mathrm{Q}_{\mathrm{V}}^{*}=\sqrt{\frac{2 \cdot \mathrm{S} \cdot \mathrm{P}}{\mathrm{H}_{\mathrm{V}}}}, \operatorname{TRC}_{\mathrm{V}}\left(\mathrm{Q}_{\mathrm{P}}^{*}\right)=\mathrm{D} \cdot \sqrt{\frac{2 \cdot \mathrm{S} \cdot \mathrm{H}_{\mathrm{V}}}{\mathrm{P}}}$.

\subsection{Joint production and ordering policy}

If the supplier follows a lot-for-lot production, the lot size corresponds to the quantity delivered. For the buyer, the order quantity corresponds to the quantity delivered. So, in the JELS solution the lot size corresponds to the order quantity, i. e. $Q_{B}=Q_{V}$. The JELS solution leads to the inventory cycles as represented in figure 1 .

Figure 1: Inventory cycles

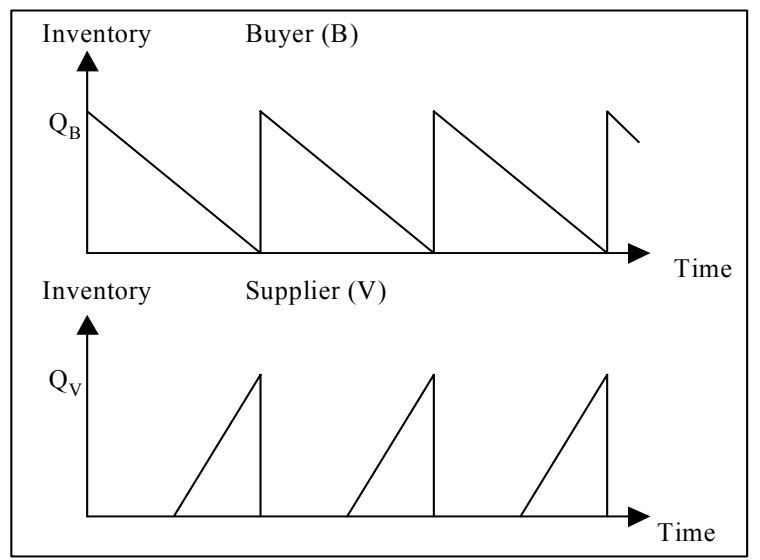

Banerjee [2] suggests a joint economic lot size (JELS) model where the objective is to minimize the total relevant costs for both the buyer and the supplier. The joint total relevant cost for the buyer and the supplier per period for a joint order quantity and lot size $\mathrm{Q}_{\mathrm{J}}=\mathrm{Q}_{\mathrm{B}}=\mathrm{Q}_{\mathrm{V}}$ can be derived from equations (1) and (4) as follows:

$\operatorname{TRC}_{J}\left(Q_{J}\right)=(A+S) \cdot \frac{D}{Q_{J}}+\frac{Q_{J}}{2} \cdot\left(H_{B}+\frac{D}{P} \cdot H_{V}\right)$.
The joint economic order quantity and lot size and the minimum total relevant cost per period for both, the buyer and the supplier, are given by

$$
\begin{aligned}
& \mathrm{Q}_{\mathrm{J}}^{*}=\sqrt{\frac{2 \cdot \mathrm{D} \cdot(\mathrm{A}+\mathrm{S})}{\mathrm{H}_{\mathrm{B}}+\frac{\mathrm{D}}{\mathrm{P}} \cdot \mathrm{H}_{\mathrm{V}}}}, \\
& \mathrm{TRC}_{\mathrm{J}}\left(\mathrm{Q}_{\mathrm{J}}^{*}\right)=\sqrt{2 \cdot \mathrm{D} \cdot(\mathrm{A}+\mathrm{S}) \cdot\left(\mathrm{H}_{\mathrm{B}}+\frac{\mathrm{D}}{\mathrm{P}} \cdot \mathrm{H}_{\mathrm{V}}\right)} .
\end{aligned}
$$

For $\mathrm{Q}_{\mathrm{B}}^{*} \neq \mathrm{Q}_{\mathrm{V}}^{*}$, obviously the most common case, the optimal joint order quantity and lot size is situated in the interval between the individual optimal solution, i. e. $\left.\mathrm{Q}_{\mathrm{J}}^{*} \in\right] \mathrm{Q}_{\mathrm{B}}^{*}, \mathrm{Q}_{\mathrm{V}}^{*}[$. Figure 2 shows the cost functions of both parties and the function of the joint total relevant cost in case of $Q_{B}^{*} \neq Q_{V}^{*}$.

Figure 2: Cost functions

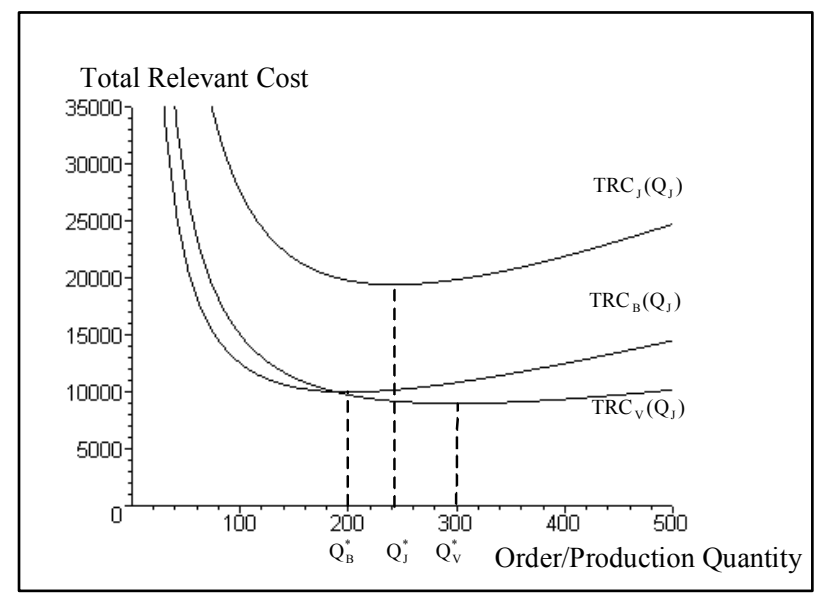

For any joint policy $\mathrm{Q}_{\mathrm{J}} \in\left[\mathrm{Q}_{\mathrm{B}}^{*}, \mathrm{Q}_{\mathrm{V}}^{*}\right]$ the buyer's total relevant cost will be

$\mathrm{TRC}_{\mathrm{B}}\left(\mathrm{Q}_{\mathrm{J}}\right)=\frac{1}{2} \cdot\left(\frac{\mathrm{Q}_{\mathrm{B}}^{*}}{\mathrm{Q}_{\mathrm{J}}}+\frac{\mathrm{Q}_{\mathrm{J}}}{\mathrm{Q}_{\mathrm{B}}^{*}}\right) \cdot \mathrm{TRC}_{\mathrm{B}}\left(\mathrm{Q}_{\mathrm{B}}^{*}\right)$,

and the supplier's total relevant cost will be

$\operatorname{TRC}_{\mathrm{V}}\left(\mathrm{Q}_{\mathrm{J}}\right)=\frac{1}{2} \cdot\left(\frac{\mathrm{Q}_{\mathrm{V}}^{*}}{\mathrm{Q}_{\mathrm{J}}}+\frac{\mathrm{Q}_{\mathrm{J}}}{\mathrm{Q}_{\mathrm{V}}^{*}}\right) \cdot \operatorname{TRC}_{\mathrm{V}}\left(\mathrm{Q}_{\mathrm{V}}^{*}\right)$, with

$\frac{1}{2} \cdot\left(\frac{\mathrm{Q}_{\mathrm{B}}^{*}}{\mathrm{Q}_{\mathrm{J}}}+\frac{\mathrm{Q}_{\mathrm{J}}}{\mathrm{Q}_{\mathrm{B}}^{*}}\right)>1 \quad \forall \mathrm{Q}_{\mathrm{j}}, \mathrm{Q}_{\mathrm{B}}^{*}>0, \mathrm{Q}_{\mathrm{j}} \neq \mathrm{Q}_{\mathrm{B}}^{*}$, and

$\frac{1}{2} \cdot\left(\frac{\mathrm{Q}_{\mathrm{V}}^{*}}{\mathrm{Q}_{\mathrm{J}}}+\frac{\mathrm{Q}_{\mathrm{J}}}{\mathrm{Q}_{\mathrm{V}}^{*}}\right)>1 \quad \forall \mathrm{Q}_{\mathrm{j}}, \mathrm{Q}_{\mathrm{V}}^{*}>0, \mathrm{Q}_{\mathrm{j}} \neq \mathrm{Q}_{\mathrm{V}}^{*}$.

If the buyer and the supplier behave individually and rationally, they select their individual optimal policies $Q_{B}^{*}$ and $Q_{V}^{*}$. Therefore, in case of $Q_{B}^{*} \neq Q_{V}^{*}$ a joint policy $Q_{J}=Q_{B}=Q_{V}$ can only result from negotiations between the parties. Should the buyer have the more powerful position to enforce his EOQ on the supplier, then no incentive 
exists for him to choose any joint policy $\left.\left.Q_{J} \in\right] Q_{B}^{*}, Q_{V}^{*}\right]$. Essentially, the relation (10) shows that the buyer will be at a disadvantage if the JELS solution is adopted. On the other side, in comparison to the individual optimal order policy of the buyer any joint policy $\left.\left.Q_{J} \in\right] Q_{B}^{*}, Q_{V}^{*}\right]$, as can bee seen from figure 2 , leads to lower total relevant cost for the supplier. Therefore, to provide an incentive to choose a joint policy the supplier can offer a side payment to the buyer. A side payment is defined as an additional monetary transfer between the parties involved that is used as an incentive for deviating from the individual optimal policy $[20 ;$ p. 22]. It is to be examined which joint policy $\mathrm{Q}_{\mathrm{J}}=\mathrm{Q}_{\mathrm{B}}=\mathrm{Q}_{\mathrm{V}}$ will result from a bargaining process between the buyer and the supplier. Assuming complete information of the parties involved, it is easy to show that the joint optimal policy $\mathrm{Q}_{\mathrm{J}}^{*}$ with an accordingly side payment of $\mathrm{z}=\mathrm{TRC}_{\mathrm{B}}\left(\mathrm{Q}_{\mathrm{J}}^{*}\right)-\mathrm{TRC}_{\mathrm{B}}\left(\mathrm{Q}_{\mathrm{B}}^{*}\right) \quad[\$ /$ period] results from negotiations. In the following section, we will analyze which joint policy $\mathrm{Q}_{\mathrm{J}}=\mathrm{Q}_{\mathrm{B}}=\mathrm{Q}_{\mathrm{V}}$ and associated side payment $\mathrm{z}$ are offered by the supplier, assuming that the buyer has private information about his function of total relevant cost.

\section{A bargaining game with asymmetric information}

In this paragraph we analyze the bargaining process between the buyer and the supplier. Therefore we will at first outline the bargaining situation. Thereupon we present a bargaining model with asymmetric information. An algorithm for the determination of optimal contracts will be presented and illustrated by a numerical example.

\subsection{The bargaining situation}

The following bargaining game belongs to the class of two-person-nonzero-sum games in which both players, the buyer and the supplier, try to maximize their individual gains. The buyer has the bargaining power to enforce his EOQ on the supplier in case of a break-down in negotiations. The supplier makes a take-it-or-leave-it-offer, i. e. in the first stage, the supplier makes an offer, and then, in the second stage, the buyer can either accept or reject and the game is immediately terminated after acceptance or refusal by the buyer [7; pp. 55-57]. It will be assumed, that the supplier has asymmetric information about the buyer's cost structure. The buyer will only select a policy other than his individual optimal policy $\mathrm{Q}_{\mathrm{B}}^{*}$ if the increase in total relevant cost resulting from this policy is compensated by the supplier. But, the buyer has no incentive to report truthfully on his cost structure. Moreover, for any joint policy $\mathrm{Q}_{\mathrm{J}}$ suggested by the supplier the buyer has an incentive to overstate the increase in his total relevant cost resulting from the suggested joint policy, $\quad \Delta \mathrm{TRC}_{\mathrm{B}}\left(\mathrm{Q}_{\mathrm{J}}, \mathrm{Q}_{\mathrm{B}}^{*}\right)=\mathrm{TRC}_{\mathrm{B}}\left(\mathrm{Q}_{\mathrm{J}}\right)-\mathrm{TRC}_{\mathrm{B}}\left(\mathrm{Q}_{\mathrm{B}}^{*}\right), \quad$ in order to obtain as high a side payment as possible.
If the supplier has incomplete information about the buyer's cost structure, different functions of the buyer's cost function may be assumed by the supplier. Therefore, the supplier must design incentive-compatible contracts which make it attractive for the buyer to choose the contract which is designed for his specific cost structure. The supplier has to offer order quantities and side payments which guarantee that the buyer accepts the adequate contract. By accepting one of these contracts the buyer indirectly reports truthfully about his cost situation. From supplier's point of view, it will be assumed that two alternative cost functions, $\operatorname{TRC}_{B}^{1}\left(Q_{B}\right)$ and $\operatorname{TRC}_{B}^{2}\left(Q_{B}\right)$, with the corresponding optimal policies $\mathrm{Q}_{\mathrm{B}, 1}^{*}, \mathrm{Q}_{\mathrm{B}, 2}^{*}$ are possible.

\subsection{The bargaining model}

Both players are assumed to be risk-neutral. Suppose, from the supplier's point of view two different cost functions are possible: the buyer's cost function is $\operatorname{TRC}_{B}^{1}\left(Q_{B}\right)$ with a probability of $\mathrm{p}_{1}>0$ and $\operatorname{TRC}_{\mathrm{B}}^{2}\left(\mathrm{Q}_{\mathrm{B}}\right)$ with a probability of $p_{2}=1-p_{1}>0$. Not being informed about the true cost it will be optimal for the supplier to offer two separate joint policies $\mathrm{Q}_{1}$ and $\mathrm{Q}_{2}$ with corresponding side payments $\mathrm{z}_{1}$ and $z_{2}$ which guarantee that the buyer accepts the adequate contract, i. e. the supplier has to offer a set of contracts. The non-linear optimization problem of the supplier is to minimize the expected value of his total cost, that is:

$$
\begin{aligned}
\min & E\left[T_{R C}\left(Q_{1}, z_{1}, Q_{2}, z_{2}\right)\right] \\
& =p_{1} \cdot\left(T_{R} C_{V}\left(Q_{1}\right)+z_{1}\right)+p_{2} \cdot\left(T_{R C}\left(Q_{2}\right)+z_{2}\right)
\end{aligned}
$$

s. t.

$$
\begin{aligned}
& \operatorname{TRC}_{\mathrm{B}}^{1}\left(\mathrm{Q}_{1}\right)-\mathrm{z}_{1} \leq \operatorname{TRC}_{\mathrm{B}}^{1}\left(\mathrm{Q}_{\mathrm{B}, 1}^{*}\right) \\
& \operatorname{TRC}_{\mathrm{B}}^{2}\left(\mathrm{Q}_{2}\right)-\mathrm{z}_{2} \leq \operatorname{TRC}_{\mathrm{B}}^{2}\left(\mathrm{Q}_{\mathrm{B}, 2}^{*}\right) \\
& \operatorname{TRC}_{\mathrm{B}}^{1}\left(\mathrm{Q}_{1}\right)-\mathrm{z}_{1} \leq \operatorname{TRC}_{\mathrm{B}}^{1}\left(\mathrm{Q}_{2}\right)-\mathrm{z}_{2} \\
& \mathrm{TRC}_{\mathrm{B}}^{2}\left(\mathrm{Q}_{2}\right)-\mathrm{z}_{2} \leq \operatorname{TRC}_{\mathrm{B}}^{2}\left(\mathrm{Q}_{1}\right)-\mathrm{z}_{1} \\
& \mathrm{Q}_{1}, \mathrm{Q}_{2}, \mathrm{z}_{1}, \mathrm{z}_{2} \geq 0
\end{aligned}
$$

Conditions (12) and (13) ensure individual rationality: it must be attractive for the buyer to accept the contract. Conditions (14) and (15) ensure incentive-compatibility, so that it is attractive for the buyer to choose the contract which is designed for the specific assumed cost structures. The optimization problem with constraints can be transformed to an unconstrained minimization problem:

$\min \mathrm{L}\left(\mathrm{Q}_{1}, \mathrm{z}_{1}, \mathrm{Q}_{2}, \mathrm{z}_{2}\right)=$

$\mathrm{p}_{1} \cdot\left(\mathrm{TRC}_{\mathrm{V}}\left(\mathrm{Q}_{1}\right)+\mathrm{z}_{1}\right)+\mathrm{p}_{2} \cdot\left(\mathrm{TRC}_{\mathrm{V}}\left(\mathrm{Q}_{2}\right)+\mathrm{z}_{2}\right)$

$-\lambda_{1} \cdot\left(\operatorname{TRC}_{\mathrm{B}}^{1}\left(\mathrm{Q}_{\mathrm{B}, 1}^{*}\right)-\mathrm{TRC}_{\mathrm{B}}^{1}\left(\mathrm{Q}_{1}\right)+\mathrm{z}_{1}\right)$

$-\lambda_{2} \cdot\left(\mathrm{TRC}_{\mathrm{B}}^{2}\left(\mathrm{Q}_{\mathrm{B}, 2}^{*}\right)-\mathrm{TRC}_{\mathrm{B}}^{2}\left(\mathrm{Q}_{2}\right)+\mathrm{z}_{2}\right)$

$-\mu_{1} \cdot\left(\operatorname{TRC}_{\mathrm{B}}^{1}\left(\mathrm{Q}_{2}\right)-\mathrm{z}_{2}-\mathrm{TRC}_{\mathrm{B}}^{1}\left(\mathrm{Q}_{1}\right)+\mathrm{z}_{1}\right)$

$-\mu_{2} \cdot\left(\operatorname{TRC}_{\mathrm{B}}^{2}\left(\mathrm{Q}_{1}\right)-\mathrm{z}_{1}-\mathrm{TRC}_{\mathrm{B}}^{2}\left(\mathrm{Q}_{2}\right)+\mathrm{z}_{2}\right)$ 
The cost functions $\mathrm{TRC}_{\mathrm{V}}, \mathrm{TRC}_{\mathrm{B}}^{1}$ and $\mathrm{TRC}_{\mathrm{B}}^{2}$ are strictly convex in $\mathrm{Q}_{1}$ and $\mathrm{Q}_{2}$. So, the Karush-Kuhn-Tucker(KKT-) conditions are sufficient for an optimal solution. For (17) the KKT-conditions can be deduced as follows:

$$
\begin{aligned}
\frac{\partial \mathrm{L}}{\partial \mathrm{Q}_{1}}= & \mathrm{p}_{1} \cdot \frac{\partial \mathrm{TRC}_{\mathrm{V}}\left(\mathrm{Q}_{1}\right)}{\partial \mathrm{Q}_{1}}+\lambda_{1} \cdot \frac{\partial \mathrm{TRC}_{\mathrm{B}}^{1}\left(\mathrm{Q}_{1}\right)}{\partial \mathrm{Q}_{1}} \\
& +\mu_{1} \cdot \frac{\partial \mathrm{TRC}_{\mathrm{B}}^{1}\left(\mathrm{Q}_{1}\right)}{\partial \mathrm{Q}_{1}}-\mu_{2} \cdot \frac{\partial \mathrm{TRC}_{\mathrm{B}}^{2}\left(\mathrm{Q}_{1}\right)}{\partial \mathrm{Q}_{1}} \geq 0 \\
\mathrm{Q}_{1} \cdot \frac{\partial \mathrm{L}}{\partial \mathrm{Q}_{1}}= & \mathrm{Q}_{1} \cdot\left(\mathrm{p}_{1} \cdot \frac{\partial \mathrm{TRC}_{\mathrm{V}}\left(\mathrm{Q}_{1}\right)}{\partial \mathrm{Q}_{1}}+\lambda_{1} \cdot \frac{\partial \mathrm{TRC}_{\mathrm{B}}^{1}\left(\mathrm{Q}_{1}\right)}{\partial \mathrm{Q}_{1}}\right. \\
& \left.+\mu_{1} \cdot \frac{\partial \mathrm{TRC}_{\mathrm{B}}^{\mathrm{l}}\left(\mathrm{Q}_{1}\right)}{\partial \mathrm{Q}_{1}}-\mu_{2} \cdot \frac{\partial \mathrm{TRC}_{\mathrm{B}}^{2}\left(\mathrm{Q}_{1}\right)}{\partial \mathrm{Q}_{1}}\right)=0 \\
\frac{\partial \mathrm{L}}{\partial \mathrm{Q}_{2}}=\mathrm{p}_{2} \cdot \frac{\partial \mathrm{TRC}_{\mathrm{V}}\left(\mathrm{Q}_{2}\right)}{\partial \mathrm{Q}_{2}}+\lambda_{2} \cdot \frac{\partial \mathrm{TRC}_{\mathrm{B}}^{1}\left(\mathrm{Q}_{2}\right)}{\partial \mathrm{Q}_{2}} & -\mu_{1} \cdot \frac{\partial \mathrm{TRC}_{\mathrm{B}}\left(\mathrm{Q}_{2}\right)}{\partial \mathrm{Q}_{2}}+\mu_{2} \cdot \frac{\partial \mathrm{TRC}_{\mathrm{B}}^{2}\left(\mathrm{Q}_{2}\right)}{\partial \mathrm{Q}_{2}} \geq 0 \\
\mathrm{Q}_{2} \cdot \frac{\partial \mathrm{L}}{\partial \mathrm{Q}_{2}}= & \mathrm{Q}_{2} \cdot\left(\mathrm{p}_{2} \cdot \frac{\partial \mathrm{TRC}_{\mathrm{V}}\left(\mathrm{Q}_{2}\right)}{\partial \mathrm{Q}_{2}}+\lambda_{2} \cdot \frac{\partial \mathrm{TRC}_{\mathrm{B}}^{\mathrm{l}}\left(\mathrm{Q}_{2}\right)}{\partial \mathrm{Q}_{2}}\right. \\
& \left.-\mu_{1} \cdot \frac{\partial \mathrm{TRC}_{\mathrm{B}}^{\mathrm{l}}\left(\mathrm{Q}_{2}\right)}{\partial \mathrm{Q}_{2}}+\mu_{2} \cdot \frac{\partial \mathrm{TRC}_{\mathrm{B}}^{2}\left(\mathrm{Q}_{2}\right)}{\partial \mathrm{Q}_{2}}\right)=0
\end{aligned}
$$

$\frac{\partial \mathrm{L}}{\partial \mathrm{z}_{1}}=\mathrm{p}_{1}-\lambda_{1}-\mu_{1}+\mu_{2} \geq 0$

$\mathrm{z}_{1} \cdot \frac{\partial \mathrm{L}}{\partial \mathrm{z}_{1}}=\mathrm{z}_{1} \cdot\left(\mathrm{p}_{1}-\lambda_{1}-\mu_{1}+\mu_{2}\right)=0$

$\frac{\partial \mathrm{L}}{\partial \mathrm{z}_{2}}=\mathrm{p}_{2}-\lambda_{2}+\mu_{1}-\mu_{2} \geq 0$

$\mathrm{z}_{2} \cdot \frac{\partial \mathrm{L}}{\partial \mathrm{z}_{2}}=\mathrm{z}_{2} \cdot\left(\mathrm{p}_{2}-\lambda_{2}+\mu_{1}-\mu_{2}\right)=0$

$-\frac{\partial \mathrm{L}}{\partial \lambda_{1}}=\mathrm{TRC}_{\mathrm{B}}^{1}\left(\mathrm{Q}_{\mathrm{B}, 1}^{*}\right)-\mathrm{TRC}_{\mathrm{B}}^{1}\left(\mathrm{Q}_{1}\right)+\mathrm{z}_{1} \geq 0$

$\lambda_{1} \cdot\left(\mathrm{TRC}_{\mathrm{B}}^{1}\left(\mathrm{Q}_{\mathrm{B}, 1}^{*}\right)-\mathrm{TRC}_{\mathrm{B}}^{1}\left(\mathrm{Q}_{1}\right)+\mathrm{z}_{1}\right)=0$

$-\frac{\partial \mathrm{L}}{\partial \lambda_{2}}=\mathrm{TRC}_{\mathrm{B}}^{2}\left(\mathrm{Q}_{\mathrm{B}, 2}^{*}\right)-\mathrm{TRC}_{\mathrm{B}}^{2}\left(\mathrm{Q}_{2}\right)+\mathrm{z}_{2} \geq 0$

$\lambda_{2} \cdot\left(\mathrm{TRC}_{\mathrm{B}}^{2}\left(\mathrm{Q}_{\mathrm{B}, 2}^{*}\right)-\mathrm{TRC}_{\mathrm{B}}^{2}\left(\mathrm{Q}_{2}\right)+\mathrm{z}_{2}\right)=0$

$-\frac{\partial \mathrm{L}}{\partial \mu_{1}}=\mathrm{TRC}_{\mathrm{B}}^{1}\left(\mathrm{Q}_{2}\right)-\mathrm{z}_{2}-\mathrm{TRC}_{\mathrm{B}}^{1}\left(\mathrm{Q}_{1}\right)+\mathrm{z}_{1} \geq 0$

$\mu_{1} \cdot\left(\mathrm{TRC}_{\mathrm{B}}^{1}\left(\mathrm{Q}_{2}\right)-\mathrm{z}_{2}-\mathrm{TRC}_{\mathrm{B}}^{1}\left(\mathrm{Q}_{1}\right)+\mathrm{z}_{1}\right)=0$

$-\frac{\partial \mathrm{L}}{\partial \mu_{2}}=\mathrm{TRC}_{\mathrm{B}}^{2}\left(\mathrm{Q}_{1}\right)-\mathrm{z}_{1}-\mathrm{TRC}_{\mathrm{B}}^{2}\left(\mathrm{Q}_{2}\right)+\mathrm{z}_{2} \geq 0$

$\mu_{2} \cdot\left(\mathrm{TRC}_{\mathrm{B}}^{2}\left(\mathrm{Q}_{1}\right)-\mathrm{z}_{1}-\mathrm{TRC}_{\mathrm{B}}^{2}\left(\mathrm{Q}_{2}\right)+\mathrm{z}_{2}\right)=0$

$\mathrm{Q}_{1}, \mathrm{Q}_{2}, \mathrm{z}_{1}, \mathrm{z}_{2}, \lambda_{1}, \lambda_{2}, \mu_{1}, \mu_{2} \geq 0$

The values of all the Lagrange's multipliers $\lambda_{1}, \lambda_{2}, \mu_{1}, \mu_{2}$ can either be zero or greater than zero.
Therefore, 16 possible combinations exist for the $\mathrm{La}$ grange's multipliers. In case of $\mathrm{Q}_{\mathrm{B}}^{*} \neq \mathrm{Q}_{\mathrm{V}}^{*}$ the side payments $\mathrm{Z}_{1}$ and $\mathrm{z}_{2}$ have to be greater than zero. With $\mathrm{z}_{1}, \mathrm{z}_{2}>0$ and the KKT-conditions (23) and (25) follows:

$\mathrm{p}_{1}-\lambda_{1}-\mu_{1}+\mu_{2}=0$

$\mathrm{p}_{2}-\lambda_{2}+\mu_{1}-\mu_{2}=0$

It applies $\mathrm{p}_{1}, \mathrm{p}_{2}>0$. Therefore, conditions (35) and (36) show that all combinations for the Lagrange's multipliers with $\lambda_{1}=\mu_{1}=0$ and $\lambda_{2}=\mu_{2}=0$ are infeasible. From substituting (35) in (36) results:

$\mathrm{p}_{2}-\lambda_{2}+\mathrm{p}_{1}-\lambda_{1}=0 \Leftrightarrow \mathrm{p}_{1}+\mathrm{p}_{2}=\lambda_{1}+\lambda_{2}$

Because of $\mathrm{p}_{1}+\mathrm{p}_{2}=1$ it applies $\lambda_{1}+\lambda_{2}=1$ and all combinations with $\lambda_{1}=\lambda_{2}=0$ are infeasible. From this analysis eight feasible cases of combinations for the Lagrange's multipliers can be determined.

Table 1: Feasible combinations

\begin{tabular}{|c|c|c|c|c|}
\hline Case & $\lambda_{1}$ & $\lambda_{2}$ & $\mu_{1}$ & $\mu_{2}$ \\
\hline 1 & $\lambda_{1}>0$ & $\lambda_{2}>0$ & $\mu_{1}=0$ & $\mu_{2}=0$ \\
\hline 2 & $\lambda_{1}>0$ & $\lambda_{2}=0$ & $\mu_{1}=0$ & $\mu_{2}>0$ \\
\hline 3 & $\lambda_{1}=0$ & $\lambda_{2}>0$ & $\mu_{1}>0$ & $\mu_{2}=0$ \\
\hline 4 & $\lambda_{1}>0$ & $\lambda_{2}>0$ & $\mu_{1}>0$ & $\mu_{2}=0$ \\
\hline 5 & $\lambda_{1}=0$ & $\lambda_{2}>0$ & $\mu_{1}>0$ & $\mu_{2}>0$ \\
\hline 6 & $\lambda_{1}>0$ & $\lambda_{2}=0$ & $\mu_{1}>0$ & $\mu_{2}>0$ \\
\hline 7 & $\lambda_{1}>0$ & $\lambda_{2}>0$ & $\mu_{1}=0$ & $\mu_{2}>0$ \\
\hline 8 & $\lambda_{1}>0$ & $\lambda_{2}>0$ & $\mu_{1}>0$ & $\mu_{2}>0$ \\
\hline
\end{tabular}

For these alternative cases six possible sets of contracts can be derived for the supplier. For each set of contracts, all constrains of (11), i. e. (12),(13),(14),(15) and (16), must be satisfied, otherwise the solution is infeasible. If one solution satisfies these constrains and the KKTconditions as well, it is an optimal solution. For the first case $\left(\lambda_{1}>0, \lambda_{2}>0, \mu_{1}=0, \mu_{2}=0\right)$ the contracts can be derived as follows. With conditions (35) and (36) and $\mu_{1}=\mu_{2}=0$ follows $\lambda_{1}=p_{1}, \lambda_{2}=p_{2}$. For $Q_{1}, Q_{2}>0$, $\mu_{1}=\mu_{2}=0, \lambda_{1}=\mathrm{p}_{1}$ and $\lambda_{2}=\mathrm{p}_{2}$ the KKT-conditions (19) and (21) can be reduced to:

$$
\begin{aligned}
& \mathrm{p}_{1} \cdot \frac{\partial \mathrm{TRC}_{\mathrm{V}}\left(\mathrm{Q}_{1}\right)}{\partial \mathrm{Q}_{1}}+\mathrm{p}_{1} \cdot \frac{\partial \mathrm{TRC}_{\mathrm{B}}^{1}\left(\mathrm{Q}_{1}\right)}{\partial \mathrm{Q}_{1}}=0 \Leftrightarrow \\
& \frac{\partial \mathrm{TRC}_{\mathrm{V}}\left(\mathrm{Q}_{1}\right)}{\partial \mathrm{Q}_{1}}=-\frac{\partial \mathrm{TRC}_{\mathrm{B}}^{1}\left(\mathrm{Q}_{1}\right)}{\partial \mathrm{Q}_{1}} \\
& \mathrm{p}_{2} \cdot \frac{\partial \mathrm{TRC}_{\mathrm{V}}\left(\mathrm{Q}_{2}\right)}{\partial \mathrm{Q}_{2}}+\mathrm{p}_{2} \cdot \frac{\partial \mathrm{TRC}_{\mathrm{B}}^{2}\left(\mathrm{Q}_{2}\right)}{\partial \mathrm{Q}_{2}}=0 \Leftrightarrow \\
& \frac{\partial \mathrm{TRC}_{\mathrm{V}}\left(\mathrm{Q}_{2}\right)}{\partial \mathrm{Q}_{2}}=-\frac{\partial \mathrm{TRC}_{\mathrm{B}}^{2}\left(\mathrm{Q}_{2}\right)}{\partial \mathrm{Q}_{2}}
\end{aligned}
$$


Conditions (38) and (39) represent the first order conditions for the joint economic order quantity and lot size as presented in paragraph 2.3. Therefore the offered joint policies are equal to the joint optimal policy, which can be derived from the JELS model. The offered payments $z_{1}$ and $z_{2}$ exactly compensate the increases of cost, induced by the transition from $Q_{B, 1}^{*}$ to $Q_{1}$ or from $Q_{B, 2}^{*}$ to $\mathrm{Q}_{2}$. For the first case it follows that:

Set of contracts number 1

$$
\begin{aligned}
& \mathrm{Q}_{1}=\sqrt{\frac{2 \cdot \mathrm{D} \cdot\left(\mathrm{A}_{1}+\mathrm{S}\right)}{\mathrm{H}}} \quad \text { with } \\
& \mathrm{z}_{1}=\mathrm{TRC}_{\mathrm{B}, 1}^{1}\left(\mathrm{Q}_{1}\right)-\mathrm{TRC}_{\mathrm{B}}^{1}\left(\mathrm{Q}_{\mathrm{B}, 1}^{*}\right) \\
& \mathrm{Q}_{2}=\sqrt{\frac{2 \cdot \mathrm{D} \cdot\left(\mathrm{A}_{2}+\mathrm{S}\right)}{\mathrm{H}_{\mathrm{B}, 2}+\frac{\mathrm{D}}{\mathrm{P}} \cdot \mathrm{H}_{\mathrm{V}}}} \text { with } \\
& \mathrm{z}_{2}=\operatorname{TRC}_{\mathrm{B}}^{2}\left(\mathrm{Q}_{2}\right)-\mathrm{TRC}_{\mathrm{B}}^{2}\left(\mathrm{Q}_{\mathrm{B}, 2}^{*}\right)
\end{aligned}
$$

This set of contracts satisfies the KKT-conditions and the constrains (12) and (13). It is an optimal solution if the conditions (14),(15) and (16) are satisfied. The sets of contracts for the other five feasible cases can be derived in a similar manner.

\section{Set of contracts number 2}

For case 2 and case 6 it follows that:

$$
\begin{aligned}
& \mathrm{Q}_{1}=\sqrt{\frac{2 \cdot \mathrm{D} \cdot\left(\mathrm{p}_{1} \cdot \mathrm{S}+\mathrm{p}_{1} \cdot \mathrm{A}_{2}+\mathrm{A}_{1}-\mathrm{A}_{2}\right)}{\mathrm{p}_{1} \cdot \frac{\mathrm{D}}{\mathrm{P}} \cdot \mathrm{H}_{\mathrm{V}}+\mathrm{p}_{1} \cdot \mathrm{H}_{\mathrm{B}, 2}+\mathrm{H}_{\mathrm{B}, 1}-\mathrm{H}_{\mathrm{B}, 2}}} \text { with } \\
& \mathrm{z}_{1}=\mathrm{TRC}_{\mathrm{B}}^{1}\left(\mathrm{Q}_{1}\right)-\mathrm{TRC}_{\mathrm{B}}^{1}\left(\mathrm{Q}_{\mathrm{B}, 1}^{*}\right) \\
& \mathrm{Q}_{2}=\sqrt{\frac{2 \cdot \mathrm{D} \cdot\left(\mathrm{A}_{2}+\mathrm{S}\right)}{\mathrm{H}_{\mathrm{B}, 2}+\frac{\mathrm{D}}{\mathrm{P}} \cdot \mathrm{H}_{\mathrm{V}}}} \text { with } \\
& \mathrm{z}_{2}=\operatorname{TRC}_{\mathrm{B}}^{2}\left(\mathrm{Q}_{2}\right)-\mathrm{TRC}_{\mathrm{B}}^{2}\left(\mathrm{Q}_{1}\right)+\mathrm{TRC}_{\mathrm{B}}^{1}\left(\mathrm{Q}_{1}\right)-\mathrm{TRC}_{\mathrm{B}}^{\mathrm{l}}\left(\mathrm{Q}_{\mathrm{B}, 1}^{*}\right)(43)
\end{aligned}
$$

This set of contracts satisfies the KKT-conditions and the constrains (12) and (15). This set of contracts is feasible and optimal if the conditions (13) and (14) are satisfied. The offered payment $z_{2}$ consists of the compensation for the increase of cost, induced by the transition from $Q_{B, 2}^{*}$ to $\mathrm{Q}_{2}$ and a bonus for not accepting the offer $\mathrm{Q}_{1}, \mathrm{z}_{1}$.

Set of contracts number 3

For case 3 and case 5 it follows that:

$$
\begin{aligned}
& \mathrm{Q}_{1}=\sqrt{\frac{2 \cdot \mathrm{D} \cdot\left(\mathrm{A}_{1}+\mathrm{S}\right)}{\mathrm{H}_{\mathrm{B}, 1}+\frac{\mathrm{D}}{\mathrm{P}} \cdot \mathrm{H}_{\mathrm{V}}}} \text { with } \\
& \mathrm{z}_{1}=\mathrm{TRC}_{\mathrm{B}}\left(\mathrm{Q}_{1}\right)-\mathrm{TRC}_{\mathrm{B}}\left(\mathrm{Q}_{2}\right)+\mathrm{TRC}_{\mathrm{B}}^{2}\left(\mathrm{Q}_{2}\right)-\mathrm{TRC}_{\mathrm{B}}^{2}\left(\mathrm{Q}_{\mathrm{B}, 2}^{*}\right)
\end{aligned}
$$

$$
\begin{aligned}
& \mathrm{Q}_{2}=\sqrt{\frac{2 \cdot \mathrm{D} \cdot\left(\mathrm{p}_{2} \cdot \mathrm{S}+\mathrm{p}_{2} \cdot \mathrm{A}_{1}+\mathrm{A}_{2}-\mathrm{A}_{1}\right)}{\mathrm{p}_{2} \cdot \frac{\mathrm{D}}{\mathrm{P}} \cdot \mathrm{H}_{\mathrm{V}}+\mathrm{p}_{2} \cdot \mathrm{H}_{\mathrm{B}, 1}+\mathrm{H}_{\mathrm{B}, 2}-\mathrm{H}_{\mathrm{B}, 1}}} \text { with } \\
& \mathrm{z}_{2}=\operatorname{TRC}_{\mathrm{B}}^{2}\left(\mathrm{Q}_{2}\right)-\mathrm{TRC}_{\mathrm{B}}^{2}\left(\mathrm{Q}_{\mathrm{B}, 2}^{*}\right)
\end{aligned}
$$

This set of contracts satisfies the KKT-conditions and the constrains (13) and (14). If the constrains (12),(15) and (16) are satisfied it is feasible a and optimal set.

Set of contracts number 4

For case 7 it follows that:

$$
\begin{aligned}
& \mathrm{Q}_{1_{1,2}}=-\frac{\mathrm{TRC}_{\mathrm{B}}^{1}\left(\mathrm{Q}_{\mathrm{B}, 1}^{*}\right)-\mathrm{TRC}_{\mathrm{B}}^{2}\left(\mathrm{Q}_{\mathrm{B}, 2}^{*}\right)}{\mathrm{H}_{\mathrm{B}, 2}-\mathrm{H}_{\mathrm{B}, 1}} \\
& \pm \sqrt{\left(\frac{\mathrm{TRC}_{\mathrm{B}}^{1}\left(\mathrm{Q}_{\mathrm{B}, 1}^{*}\right)-\mathrm{TRC}_{\mathrm{B}}^{2}\left(\mathrm{Q}_{\mathrm{B}, 2}^{*}\right)}{\mathrm{H}_{\mathrm{B}, 2}-\mathrm{H}_{\mathrm{B}, 1}}\right)^{2}-\frac{2 \cdot \mathrm{D} \cdot\left(\mathrm{A}_{2}-\mathrm{A}_{1}\right)}{\mathrm{H}_{\mathrm{B}, 2}-\mathrm{H}_{\mathrm{B}, 1}}}
\end{aligned}
$$

with $\mathrm{z}_{1}=\operatorname{TRC}_{\mathrm{B}}^{1}\left(\mathrm{Q}_{1}\right)-\mathrm{TRC}_{\mathrm{B}}^{1}\left(\mathrm{Q}_{\mathrm{B}, 1}^{*}\right)$

$\mathrm{Q}_{2}=\sqrt{\frac{2 \cdot \mathrm{D} \cdot\left(\mathrm{A}_{2}+\mathrm{S}\right)}{\mathrm{H}_{\mathrm{B}, 2}+\frac{\mathrm{D}}{\mathrm{P}} \cdot \mathrm{H}_{\mathrm{V}}}} \quad$ with

$\mathrm{z}_{2}=\mathrm{TRC}_{\mathrm{B}}^{2}\left(\mathrm{Q}_{2}\right)-\mathrm{TRC}_{\mathrm{B}}^{2}\left(\mathrm{Q}_{\mathrm{B}, 2}^{*}\right)$

The set of contracts satisfies the constrains (12),(13) and (14). It is an optimal set of contracts since the constrains (15) and (16) are satisfied and $\mu_{2}>0$ as well. It applies $\mu_{2}>0$ if the following conditions is satisfied:

$$
\frac{\mathrm{p}_{1} \cdot\left(\frac{1}{2} \cdot\left(\frac{\mathrm{D}}{\mathrm{P}} \cdot \mathrm{H}_{\mathrm{V}}+\mathrm{H}_{\mathrm{B}, 1}\right)-\left(\mathrm{S}+\mathrm{A}_{1}\right) \cdot \frac{\mathrm{D}}{\mathrm{Q}_{1}^{2}}\right)}{\frac{1}{2} \cdot\left(\mathrm{H}_{\mathrm{B}, 2}-\mathrm{H}_{\mathrm{B}, 1}\right)+\left(\mathrm{A}_{1}-\mathrm{A}_{2}\right) \cdot \frac{\mathrm{D}}{\mathrm{Q}_{1}^{2}}}>0
$$

Set of contracts number 5

For case 4 it follows that:

$$
\begin{aligned}
& \mathrm{Q}_{1}=\sqrt{\frac{2 \cdot \mathrm{D} \cdot\left(\mathrm{A}_{1}+\mathrm{S}\right)}{\mathrm{H}_{\mathrm{B}, 1}+\frac{\mathrm{D}}{\mathrm{P}} \cdot \mathrm{H}_{\mathrm{V}}}} \text { with } \\
& \mathrm{z}_{1}=\mathrm{TRC}_{\mathrm{B}}^{1}\left(\mathrm{Q}_{1}\right)-\mathrm{TRC}_{\mathrm{B}}^{1}\left(\mathrm{Q}_{\mathrm{B}, 1}^{*}\right) \\
& \mathrm{Q}_{2_{1,2}}=-\frac{\mathrm{TRC}_{\mathrm{B}}^{2}\left(\mathrm{Q}_{\mathrm{B}, 2}^{*}\right)-\mathrm{TRC}_{\mathrm{B}}^{1}\left(\mathrm{Q}_{\mathrm{B}, 1}^{*}\right)}{\mathrm{H}_{\mathrm{B}, 1}-\mathrm{H}_{\mathrm{B}, 2}} \\
& \pm \sqrt{\left(\frac{\left.\mathrm{TRC}_{\mathrm{B}}^{2}\left(\mathrm{Q}_{\mathrm{B}, 2}^{*}\right)-\mathrm{TRC}_{\mathrm{B}}^{1}\left(\mathrm{Q}_{\mathrm{B}, 1}^{*}\right)\right)^{2}-\frac{2 \cdot \mathrm{D} \cdot\left(\mathrm{A}_{1}-\mathrm{A}_{2}\right)}{\mathrm{H}_{\mathrm{B}, 1}-\mathrm{H}_{\mathrm{B}, 2}}}{\mathrm{H}_{\mathrm{B}, 1}-\mathrm{H}_{\mathrm{B}, 2}}\right.}
\end{aligned}
$$

with $\mathrm{z}_{2}=\mathrm{TRC}_{\mathrm{B}}^{2}\left(\mathrm{Q}_{2}\right)-\mathrm{TRC}_{\mathrm{B}}^{2}\left(\mathrm{Q}_{\mathrm{B}, 2}^{*}\right)$

The constrains (12),(13),(15) are satisfied. This set of contracts is feasible and optimal, if conditions (14),(16) and $\mu_{1}>0$ are satisfied. For $\mu_{1}>0$ the following conditions must be satisfied: 


$$
\frac{\mathrm{p}_{2} \cdot\left(\frac{1}{2} \cdot\left(\frac{\mathrm{D}}{\mathrm{P}} \cdot \mathrm{H}_{\mathrm{V}}+\mathrm{H}_{\mathrm{B}, 2}\right)-\left(\mathrm{S}+\mathrm{A}_{2}\right) \cdot \frac{\mathrm{D}}{\mathrm{Q}_{2}^{2}}\right)}{\frac{1}{2} \cdot\left(\mathrm{H}_{\mathrm{B}, 1}-\mathrm{H}_{\mathrm{B}, 2}\right)+\left(\mathrm{A}_{2}-\mathrm{A}_{1}\right) \frac{\mathrm{D}}{\mathrm{Q}_{2}^{2}}}>0
$$

Set of contracts number 6

For case 8 it follows that:

$$
\begin{aligned}
& \mathrm{Q}_{1,2}=-\frac{\operatorname{TRC}_{\mathrm{B}}^{1}\left(\mathrm{Q}_{\mathrm{B}, 1}^{*}\right)-\mathrm{TRC}_{\mathrm{B}}^{2}\left(\mathrm{Q}_{\mathrm{B}, 2}^{*}\right)}{\mathrm{H}_{\mathrm{B}, 2}-\mathrm{H}_{\mathrm{B}, 1}} \\
& \pm \sqrt{\left(\frac{\left.\operatorname{TRC}_{\mathrm{B}}^{1}\left(\mathrm{Q}_{\mathrm{B}, 1}^{*}\right)-\mathrm{TRC}_{\mathrm{B}}^{2}\left(\mathrm{Q}_{\mathrm{B}, 2}^{*}\right)\right)^{2}-\frac{2 \cdot \mathrm{D} \cdot\left(\mathrm{A}_{2}-\mathrm{A}_{1}\right)}{\mathrm{H}_{\mathrm{B}, 2}-\mathrm{H}_{\mathrm{B}, 1}}}{\mathrm{H}_{\mathrm{B}, 2}-\mathrm{H}_{\mathrm{B}, 1}}\right.}
\end{aligned}
$$

with $\mathrm{z}_{1}=\operatorname{TRC}_{\mathrm{B}}^{1}\left(\mathrm{Q}_{1}\right)-\operatorname{TRC}_{\mathrm{B}}^{1}\left(\mathrm{Q}_{\mathrm{B}, 1}^{*}\right)$

$$
\mathrm{Q}_{2_{1,2}}=-\frac{\operatorname{TRC}_{\mathrm{B}}^{2}\left(\mathrm{Q}_{\mathrm{B}, 2}^{*}\right)-\operatorname{TRC}_{\mathrm{B}}^{1}\left(\mathrm{Q}_{\mathrm{B}, 1}^{*}\right)}{\mathrm{H}_{\mathrm{B}, 1}-\mathrm{H}_{\mathrm{B}, 2}}
$$$$
\pm \sqrt{\left(\frac{\operatorname{TRC}_{B}^{2}\left(Q_{B, 2}^{*}\right)-T R C_{B}^{1}\left(Q_{B, 1}^{*}\right)}{\mathrm{H}_{B, 1}-H_{B, 2}}\right)^{2}-\frac{2 \cdot D \cdot\left(A_{1}-A_{2}\right)}{H_{B, 1}-H_{B, 2}}}
$$

with $\mathrm{z}_{2}=\mathrm{TRC}_{\mathrm{B}}^{2}\left(\mathrm{Q}_{2}\right)-\mathrm{TRC}_{\mathrm{B}}^{2}\left(\mathrm{Q}_{\mathrm{B}, 2}^{*}\right)$

This set of contracts is feasible and optimal, if conditions (16),(48) and (51) are satisfied.

The supplier can determine an optimal set of contracts for the buyer's assumed cost functions $\operatorname{TRC}_{B}^{1}\left(Q_{B}\right)$ and $\operatorname{TRC}_{B}^{2}\left(Q_{B}\right)$. If the buyer behaves rationally, it is attractive for him to choose the contract which is designed for his specific cost structure. The expected value of the supplier's bargaining surplus is given by the difference between the expected value of his total relevant cost with and without bargaining:

$$
\begin{aligned}
& -\mathrm{p}_{1} \cdot\left(\operatorname{TRC}_{\mathrm{V}}\left(\mathrm{Q}_{1}\right)+\mathrm{z}_{1}\right) \\
& -\mathrm{p}_{2} \cdot\left(\operatorname{TRC}_{\mathrm{V}}\left(\mathrm{Q}_{2}^{*}\right)+\mathrm{z}_{2}\right)
\end{aligned}
$$$$
\mathrm{E}\left[\pi_{\mathrm{V}}\left(\mathrm{Q}_{1}, \mathrm{Q}_{2}\right)\right]=\mathrm{p}_{1} \cdot \mathrm{TRC}_{\mathrm{V}}\left(\mathrm{Q}_{\mathrm{B}, 1}^{*}\right)+\mathrm{p}_{2} \cdot \mathrm{TRC}_{\mathrm{V}}\left(\mathrm{Q}_{\mathrm{B}, 2}^{*}\right)
$$

The expected value of supplier's bargaining surplus for the derived sets of contracts are:

For the sets of contracts number 1,4,5 and 6:

$$
\begin{aligned}
& \mathrm{E}\left[\pi_{\mathrm{V}}\left(\mathrm{Q}_{1}, \mathrm{Q}_{2}\right)\right]=\mathrm{p}_{1} \cdot\left(\operatorname{TRC}_{\mathrm{V}}\left(\mathrm{Q}_{\mathrm{B}, 1}^{*}\right)-\operatorname{TRC}_{\mathrm{V}}\left(\mathrm{Q}_{1}\right)\right. \\
& \left.-\operatorname{TRC}_{\mathrm{B}}^{1}\left(\mathrm{Q}_{1}\right)+\operatorname{TRC}_{\mathrm{B}}^{1}\left(\mathrm{Q}_{\mathrm{B}, 1}^{*}\right)\right)+\mathrm{p}_{2} \cdot\left(\operatorname{TRC}_{\mathrm{V}}\left(\mathrm{Q}_{\mathrm{B}, 2}^{*}\right)\right. \\
& \left.-\mathrm{TRC}_{\mathrm{V}}\left(\mathrm{Q}_{2}\right)-\operatorname{TRC}_{\mathrm{B}}^{2}\left(\mathrm{Q}_{2}\right)+\operatorname{TRC}_{\mathrm{B}}^{2}\left(\mathrm{Q}_{\mathrm{B}, 2}^{*}\right)\right)
\end{aligned}
$$

For the set of contracts number 2 :

$$
\begin{aligned}
& E\left[\pi_{V}\left(Q_{1}, Q_{2}\right)\right]=p_{1} \cdot\left(\operatorname{TRC}_{V}\left(Q_{B, 1}^{*}\right)-\operatorname{TRC}_{V}\left(Q_{1}\right)\right. \\
& \left.-\operatorname{TRC}_{B}^{1}\left(Q_{1}\right)+\operatorname{TRC}_{B}^{1}\left(Q_{B, 1}^{*}\right)\right)+p_{2} \cdot\left(\operatorname{TRC}_{V}\left(Q_{B, 2}^{*}\right)\right. \\
& -\operatorname{TRC}_{V}\left(Q_{2}\right)-\operatorname{TRC}_{B}^{2}\left(Q_{2}\right)+\operatorname{TRC}_{B}^{2}\left(Q_{1}\right) \\
& \left.-\operatorname{TRC}_{B}^{1}\left(Q_{1}\right)+\operatorname{TRC}_{B}^{1}\left(Q_{B, 1}^{*}\right)\right) \\
& \text { Finally, for the set of contracts number 3: }
\end{aligned}
$$

$$
\begin{aligned}
& \mathrm{E}\left[\pi_{\mathrm{V}}\left(\mathrm{Q}_{1}, \mathrm{Q}_{2}\right)\right]=\mathrm{p}_{1} \cdot\left(\operatorname{TRC}_{\mathrm{V}}\left(\mathrm{Q}_{\mathrm{B}, 1}^{*}\right)-\mathrm{TRC}_{\mathrm{V}}\left(\mathrm{Q}_{1}\right)\right. \\
& -\operatorname{TRC}_{\mathrm{B}}^{1}\left(\mathrm{Q}_{1}\right)+\operatorname{TRC}_{\mathrm{B}}^{1}\left(\mathrm{Q}_{2}\right)-\operatorname{TRC}_{\mathrm{B}}^{2}\left(\mathrm{Q}_{2}\right) \\
& \left.+\operatorname{TRC}_{\mathrm{B}}^{2}\left(\mathrm{Q}_{\mathrm{B}, 2}^{*}\right)\right)+\mathrm{p}_{2} \cdot\left(\operatorname{TRC}_{\mathrm{V}}\left(\mathrm{Q}_{\mathrm{B}, 2}^{*}\right)-\mathrm{TRC}_{\mathrm{V}}\left(\mathrm{Q}_{2}\right)\right. \\
& \left.-\operatorname{TRC}_{\mathrm{B}}^{2}\left(\mathrm{Q}_{2}\right)+\operatorname{TRC}_{\mathrm{B}}^{2}\left(\mathrm{Q}_{\mathrm{B}, 2}^{*}\right)\right)
\end{aligned}
$$

\subsection{An example}

The algorithm for the determination of optimal contracts, presented in the preceding paragraph, will now be illustrated by a numerical example. We will consider the supplier-buyer-relationship between an electronics company and a car manufacturer in Germany. The electronics company, the supplier, produces several electronic components for a number of car manufacturers in Europe. One of these components is a control system for a cooler, which is exclusively produced for a German car manufacturer. A 5year contract between the two companies specifies the conditions of the supplier partnership. The buyer is responsible for construction specifications. The relationship is asymmetric, the buyer has the final decision in most respects. The contract is based on the lifetime of the model and the buyer is free to choose another supplier when the model is replaced. The buyer's order policy is based on an one-year blanket purchase order for the control system. The monthly demand is quasi-deterministic and constant. Thus the buyer will place his order based on his EOQ. From past orders the supplier anticipates an EOQ of $\mathrm{Q}_{\mathrm{B}, 1}^{*}=200$ or $\mathrm{Q}_{\mathrm{B}, 2}^{*}=150$. The electronics company employs a lot-forlot-policy. Consider the following information for both assumed cost structures of the buyer based on possibilities for buyer's EOQ and for the supplier in table 2, with the assumed probabilities of $\mathrm{p}_{1}=\mathrm{p}_{2}=0,5$, the demand $\mathrm{b}=10000$ and the supplier's production capacity $\mathrm{d}=15000$.

Table 2: Data of the example

\begin{tabular}{|c|c|c|}
\hline Supplier & $\begin{array}{c}\text { Buyer } \\
\left(\text { with } \mathrm{p}_{1}=0,5\right)\end{array}$ & $\begin{array}{c}\text { Buyer } \\
\left.\text { (with } \mathrm{p}_{2}=0,5\right)\end{array}$ \\
\hline $\mathrm{S}=135$, & $\mathrm{A}_{1}=100$, & $\mathrm{A}_{2}=90$, \\
$\mathrm{H}_{\mathrm{V}}=45$ & $\mathrm{H}_{\mathrm{B}, 1}=50$ & $\mathrm{H}_{\mathrm{B}, 2}=80$ \\
\hline $\mathrm{Q}_{\mathrm{V}}^{*}=300$ & $\mathrm{Q}_{\mathrm{B}, 1}^{*}=200$ & $\mathrm{Q}_{\mathrm{B}, 2}^{*}=150$ \\
\hline $\mathrm{TRC}_{\mathrm{V}}\left(\mathrm{Q}_{\mathrm{V}}^{*}\right)=$ & $\mathrm{TRC}_{\mathrm{B}}^{1}\left(\mathrm{Q}_{\mathrm{B}, 1}^{*}\right)=$ & $\mathrm{TRC}_{\mathrm{B}}^{2}\left(\mathrm{Q}_{\mathrm{B}, 2}^{*}\right)=$ \\
9000 & 10000 & 12000 \\
\hline
\end{tabular}

For the next six month the supplier needs to determine an offer, consisting of the supplied quantity and the side payment. This offer should include an incentive for the buyer to deviate from his EOQ in order to reduce the total relevant cost of the supplier. Without bargaining, the total relevant cost of the supplier will be $\mathrm{TRC}_{\mathrm{V}}\left(\mathrm{Q}_{\mathrm{B}, 1}^{*}\right)=9750$ if buyer's true cost function is given by $\mathrm{TRC}_{\mathrm{B}}^{1}\left(\mathrm{Q}_{\mathrm{B}}\right)$ and 
$\operatorname{TRC}_{\mathrm{V}}\left(\mathrm{Q}_{\mathrm{B}, 2}^{*}\right)=11250$ if $\operatorname{TRC}_{\mathrm{B}}^{2}\left(\mathrm{Q}_{\mathrm{B}}\right)$ is the true cost function of the buyer. Without bargaining the expected value of the total relevant cost of the supplier amounts to $\mathrm{E}\left[\mathrm{TRC}_{\mathrm{V}}\left(\mathrm{Q}_{1}=200, \mathrm{z}_{1}=0, \mathrm{Q}_{2}=150, \mathrm{z}_{2}=0\right)\right]=10500$.

With the given data structure the sets of contracts $2,4,5$ and 6 are infeasible because of determined side payments $z_{1}, z_{2}<0$ and/or offers $Q_{1}, Q_{2}<0$. The set of contracts number 1 is infeasible for (11) because condition (14) is not satisfied. This set of contracts is given by $\mathrm{Q}_{1}=242,38, \mathrm{z}_{1}=185,28, \mathrm{Q}_{2}=202,26, \mathrm{z}_{2}=540,12$. If the true cost structure of the buyer is given by $\operatorname{TRC}_{\mathrm{B}}^{1}\left(\mathrm{Q}_{\mathrm{B}}\right)$ the buyer has an incentive to accept the contract $Q_{2}=202,26, z_{2}=540,12$ which is made based on the assumed cost function $\operatorname{TRC}_{B}^{2}\left(Q_{B}\right)$. In this case applies $\operatorname{TRC}_{\mathrm{B}}^{1}\left(\mathrm{Q}_{2}\right)-\mathrm{z}_{2}=9460,51<\mathrm{TRC}_{\mathrm{B}}^{1}\left(\mathrm{Q}_{1}\right)-\mathrm{z}_{1}=10000$ and the total relevant cost of the supplier will be $\mathrm{TRC}_{\mathrm{V}}\left(\mathrm{Q}_{2}, \mathrm{Z}_{2}\right)=10248,45$. The set of contracts number 3 is optimal for the supplier. This set of contracts is incentive-compatible, i. e. it is attractive for the buyer to choose the contract which is designed for his specific cost structure. For the optimal set of contracts number 3, $\mathrm{Q}_{1}=242,38, \mathrm{z}_{1}=243,39, \mathrm{Q}_{2}=175,25, \mathrm{z}_{2}=145,52$, the expected value of the total relevant cost of the supplier amounts to $E\left[T R C_{\mathrm{V}}\right]=9963,20$. The supplier realizes

$\operatorname{TRC}_{\mathrm{V}}\left(\mathrm{Q}_{1}, \mathrm{z}_{1}\right)=9448,85$ if buyer's true cost function is $\operatorname{TRC}_{B}^{1}\left(Q_{B}\right)$. He realizes $\operatorname{TRC}_{V}\left(Q_{2}, z_{2}\right)=10477,55$ if the true cost function is $\operatorname{TRC}_{B}^{2}\left(Q_{B}\right)$. With bargaining the supplier's expected bargaining surplus is given by $\mathrm{E}\left[\pi_{\mathrm{V}}\left(\mathrm{Q}_{1}, \mathrm{Q}_{2}\right)\right]=536,80$.

\section{The software application DOSO}

In association with Hulocon Huth Logistics Consulting [www.hulocon.de] the algorithm for the determination of the optimal set of contracts, presented in the preceding paragraph, was implemented in the software application DOSO (Determination of the optimal set of contracts). $D O S O$ is an interactive application running under Microsoft Windows that enables the user to determine the optimal set of contracts.

Figure 3 shows the graphical user interface of DOSO. The user interface is split in two different areas. The area on the left hand side is used for data entry. The user enters all relevant planning data, i. e. demand, production rate, set up cost, inventory holding cost and the assumed cost structures of the buyer. Figure 3 shows the relevant data of the example presented in the preceding paragraph. The area on the right hand side is used for displaying the computational results. Figure 3 shows the individual optimal solutions for the supplier and for both assumed cost structures of the buyer as well as the underlying cost curves. Beside the display of the individual optimal solutions, the program computes the six possible sets of contracts and evaluates the optimal set. These computational results can also be displayed using the area on the right hand side. Figure 4 shows that of the six possible sets of contracts, number 3 is optimal. For the set of contracts number 1 the condition (14) is not satisfied. Therefore the set of contracts number 1 is feasible but sub-optimal. The sets of contracts number 2, 4, 5 and 6 lead to solutions infeasible, with $z_{1}<0$ and/or $z_{2}<0$. As can be seen from figure 4 , the program displays the results of the computation and evaluation using different colors for infeasible and sub-optimal sets and for the optimal set of contracts. Moreover, for suboptimal sets of contracts the application displays the gain of the buyer if he accepts a contract which is not designed for his cost structure.

A joint planning process between buyers and suppliers is supported by software systems as Enterprise Resource Planning Systems (ERP) and Advanced Planning Systems (APS). These systems support information management between supply chain partners and a joint planning process. The APS Advanced Planner and Optimizer (APO) of SAP, for example, provides a module called SAP APO Collaborative Planning. Using this module requested order quantities and delivery dates of the buyer can be forwarded to the supplier via internet. The supplier can accept these orders or change the quantities or delivery dates. The resulting deviations are displayed by an "Alert-Monitor". If the buyer does not accept the changes they must negotiate on order quantities and delivery dates. However, the bargaining process between buyers and suppliers in supply chains are not supported by these systems.

The application DOSO is a software based negotiation support system which can be implemented in ERP and APS. Using DOSO the supplier is able to generate sets of contracts which can be forwarded to the buyer via internet. If the buyer refuses the contracts the supplier generates another set of contracts in consideration of other possible cost structures of the buyer. Therefore DOSO can significantly enhance order quantity and due date functionalities of ERP and APS.

\section{Conclusion}

In this paper a joint order and production policy is developed as a bargaining solution. If the buyer has the more powerful position to enforce his individual optimal order policy on the supplier then no incentive exists for the buyer to choose a cooperative order and production policy. A joint policy therefore can only be the result of a bargaining process between the buyer and the supplier. The research presented in this paper offers a bargaining model with asymmetric information about buyer's holding cost and ordering cost assuming that the buyer has the bargaining power to enforce his EOQ on the supplier in case of breakdown in negotiations. It was shown that the screening succeeds if the supplier can estimate the possible cost structure of the buyer sufficiently exact. 
Figure 3: User interface of $D O S O$

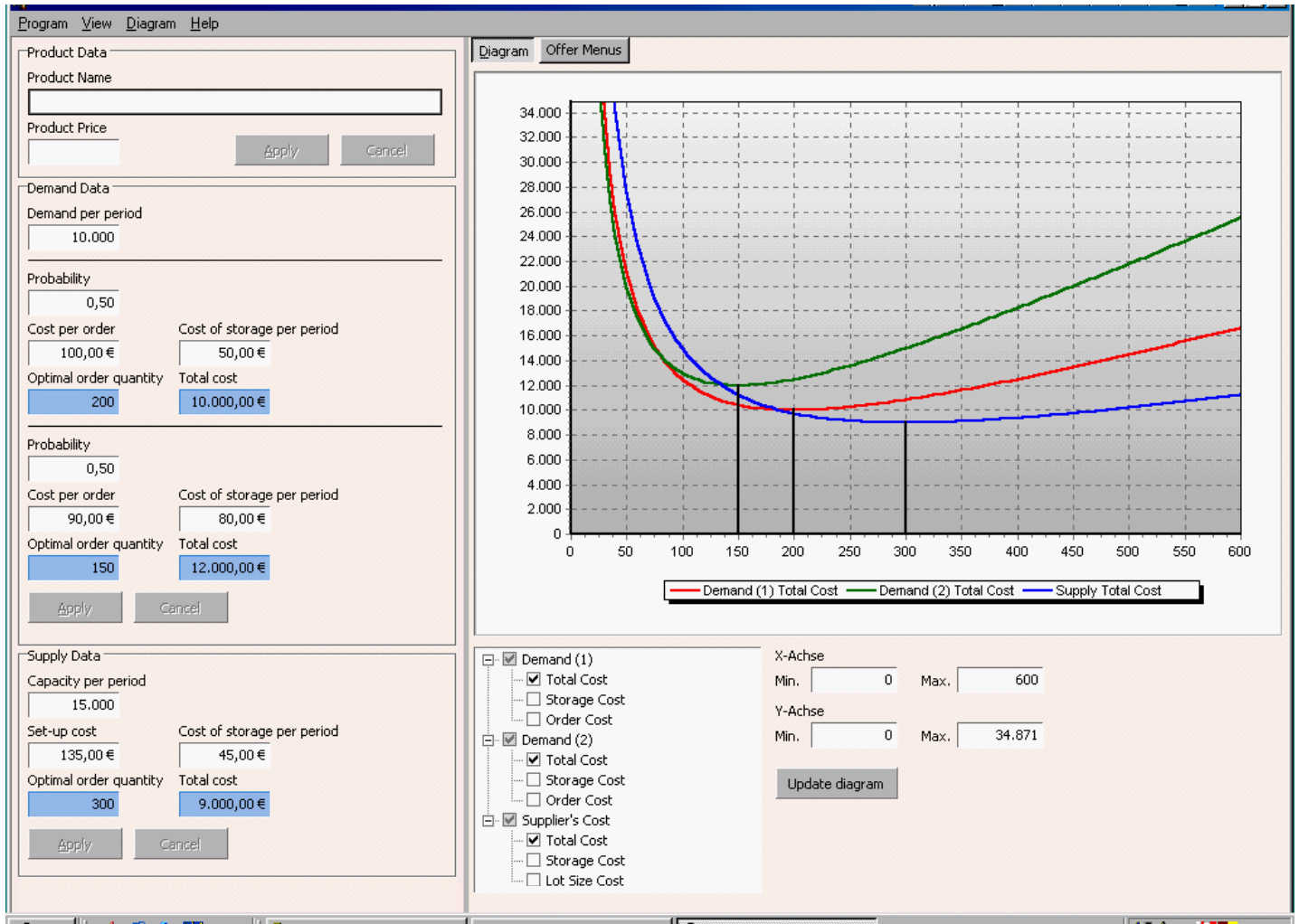

Figure 4: Representation of the sets of contracts in DOSO

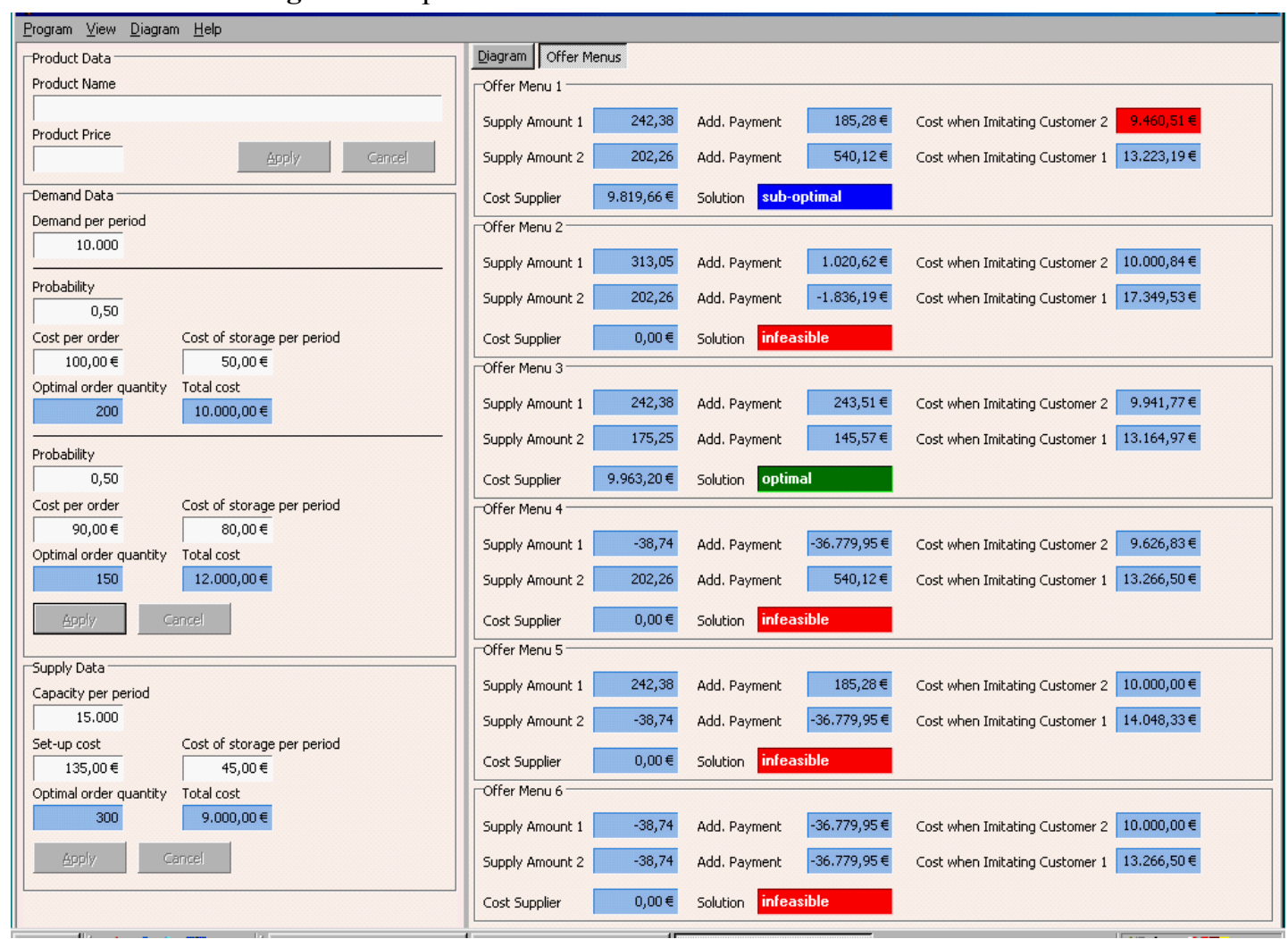


Thus, complete information of both players, the buyer and the supplier, does not represent a necessary prerequisite for a bargaining solution.

The presented model was restricted to the case of two possible cost structures of the buyer. It can also be extended to $n>2$ assumed cost structures. In this case $n \cdot(n-1)$ incentive-compatibility conditions exist. Every offered contract has to be compared with n-1 other contracts. However, in practice it is not feasible to offer a more than two contracts. Another important practical issue should also be considered: In order to derive the set of contracts the supplier must obtain the assumed cost structures of the buyer. While the buyer's periodically demand can be inferred from his past ordering behavior, it is very difficult to estimate buyer's holding and ordering costs. However, the buyer's holding cost can be specified as an implicit function of his ordering cost and his EOQ and, likewise, the buyer's ordering cost can be specified as an implicit function of his holding cost and his EOQ. The relative insensitivity of the optimal solution permits the establishment of a "good" set of contracts.

\section{References}

[1] Agrawal, A. K./Raju, D. A. (1996): Improved joint economic lot size model for a purchaser and a vendor, in: Khan, M. K./Wright, C. S./Whalley, R. (Eds.): Advanced Manufacturing Processes, Systems, and Technologies (AMPST 96), London, pp. 579-587.

[2] Banerjee, A. (1986a): A Joint Economic-Lot-Size Model for Purchaser and Vendor, in: Decision Sciences, Vol. 17, pp. 292-311.

[3] Banerjee, A. (1986b): On "A Quantity Discount Pricing Model to Increase Vendor Profits“, in: Management Science, Vol. 32, No. 11, pp. 1513-1517.

[4] Bramel, J., Simchi-Levi, D. (1997). The Logic of Logistics - Theory, Algorithm, and Applications for Logistics Management, New York.

[5] Chatterjee, A. K./Ravi, R. (1991): Joint Economic Lot-Size Model with Delivery in Sub-Batches, in: Opsearch, Vol. 28, No. 2, pp. 118-124.

[6] Corbett, Ch. J., de Groote, X. (2000): A Supplier's Optimal Quantity Discount Policy under Asymmetric Information, in: Management Science, Vol. 46, No. 3, pp. 444-450.

[7] Eichberger, J. (1993): Game theory for economists, San Diego, London.

[8] Goyal, S. K. (1976): An integrated inventory Model for a single supplier-single customer problem, in: International Journal of Production Research, Vol. 15, No. 1, pp. 107-111.

[9] Goyal, S. K. (1988): "A joint economic-lot-size model for purchaser and vendor": a comment, in: Decision Sciences, Vol. 19, pp. 236-241.

[10] Goyal, S. K., Gupta, Y. P. (1989): Integrated inventory models: The buyer-vendor coordination, in:
European Journal of Operational Research, Vol. 41, pp. 261-269.

[11] Hill, R. M. (1997): The single-vendor single-buyer integrated production-inventory model with a generalised policy, in: European Journal of Operational Research, No. 97, pp. 493-499.

[12] Illing, G. (1992): Private Information as Transaction Costs: The Coase Theorem Revisited, in: Journal of Institutional and Theoretical Economics, Vol. 148, pp. 558-576.

[13] Joglekar, P. N. (1988): Comments on "A Quantity Discount Pricing Model to Increase Vendor Profits“, in: Management Science, Vol. 34, No. 11, pp. 13911398.

[14] Joglekar, P. N. , Tharthare, S. (1990): The Individually Responsible and Rational Decision Approach to Economic Lot Size for One Vendor and many Purchasers, in: Decision Sciences, Vol. 21, pp. 492-506.

[15] Johnson, M. E./Pyke, D. F. (2001): Supply Chain Management, in: Gass, S. I./Harris, C. M. (Eds.): Encyclopaedia of Operations Research and Management Science, Centennial Edition, Boston, pp. 794-806.

[16] Landeros, R., Lyth, D. M. (1989): Economic-lot-size models for cooperative inter-organizational relationships, in: Journal of Business Logistics, Vol. 10, No. 2, pp. 146-158.

[17] Lu, L. (1995): A one-vendor multi-buyer integrated inventory model, in: European Journal of Operational Research, Vol. 81, pp. 312-323.

[18] Lee, H. L./Rosenblatt, M. J. (1986): A Generalized Quantity Discount Pricing Model to Increase Supplier's Profits, in: Management Science, Vol. 32, No. 9, pp. 1177-1185.

[19] Monahan, J. P. (1984): A Quantity Discount Pricing Model to Increase Vendor Profits, in: Management Science, Vol. 30, No. 6, pp. 720-726.

[20] Rubin, P. A., Carter, J. R. (1990): Joint Optimality in Buyer-Supplier Negotiations, in: Journal of Purchasing and Materials Management, Spring 1990, pp. 2026.

[21] Sharafali, M./Co, H. C. (2000): Some models for understanding the cooperation between the supplier and the buyer, in: International Journal of Production Research, Vol. 38, No. 15, pp. 3425-3449.

[22] Silver, E. A./Pyke, D. F./Peterson, R. (1998): Inventory Management and Production Planning and Scheduling, Third Edition, New York.

[23] Thomas, D. J./Griffin, P. M. (1996): Coordinated supply chain management, in: European Journal of Operational research, Vol. 94, pp. 1-15. 